\title{
Internet e democratização do conhecimento: repensando o processo de exclusão social ${ }^{1}$
}

\author{
TEIXEIRA, Adriano Canabarro ${ }^{2}$ \\ BRANDÃO, Edemilson Jorge Ramos ${ }^{3}$
}

\begin{abstract}
Resumo: Nesse estudo, analisou-se as potencialidades educacionais da Internet como elemento de democratização do conhecimento na sociedade da informação, partindo do princípio de que representa um poderoso elemento à disposição da educação e, uma vez utilizada de modo a fornecer aos indivíduos um ambiente propício ao seu desenvolvimento individual e, principalmente, coletivo, pode constituir-se num importante instrumento para a superação do quadro de exclusão e seletividade social a que está submetida uma grande parcela da população brasileira.
\end{abstract}

Palavras-chave: Internet, democratização do conhecimento, sociedade da informação.

\section{Introdução}

No novo contexto social que se configura e em razão da presença cada vez maior de tecnologias na vida dos indivíduos, o recurso estratégico passa a ser a informação. Conseqüentemente, quem não tem acesso à informação estará à margem desta nova sociedade, instituindo-se, assim, uma nova modalidade de exclusão social no século XXI, referida por muitos teóricos como "divisão digital". Tal forma de seletividade pode ser classificada como uma divisão entre aqueles indivíduos que, entre outras coisas, não possuem acesso à informação e aqueles que a têm em abundância.

Vale ressaltar, entretanto, que o acesso à informação, por si só, não constitui um elemento de superação dessa nova modalidade de seletividade. É preciso que as informações sejam sistematizadas, analisadas, discutidas, apropriadas, aplicadas ou descartadas, a fim de possibilitarem a construção efetiva de conhecimento. Uma vez sistematizadas como conhecimento, as "novas" informações passam também a ser disponibilizadas para que outros indivíduos ou grupos possam igualmente beneficiar-se, formando-se, assim, um ciclo que deverá repetir-se indefinidamente, no qual informação gera conhecimento, que, por sua vez, gera informação, que gera conhecimento, e assim sucessivamente, o que acaba por desenvolver no indivíduo uma crescente capacidade de interação com os outros e com novos conhecimentos cada vez mais complexos.

Em razão de suas características, serviços e potencialidades, a rede Internet pode ser considerada como um importante recurso à disposição da educação, não somente pela sua capacidade de disseminação de informação, mas, também, pela possibilidade

\footnotetext{
${ }^{1}$ Trabalho apresentado no WIE 2002 - SBC

${ }^{2}$ Professor, MSc., Universidade de Passo Fundo, teixeira@upf.br, https://vitoria.upf.tche.br/ teixeira

${ }^{3}$ Professor, Dr., Universidade de Passo Fundo, brandao@upf.br, https://vitoria.upf.tche.br/ brandao 
de construção do conhecimento através de experiências em que predominem a comunicação e a colaboração.

A análise de temas relacionados à Internet como elemento de democratização do conhecimento, bem como de suas potencialidades pedagógicas e emancipatórias, se, por um lado, suscita vários questionamentos e estudos científicos, pela amplitude e contemporaneidade das questões envolvidas, por outro, constitui um evidente estímulo à reflexão sobre importantes questões que envolvem a escola e a sociedade como um todo, a saber: a questão da formação docente para a utilização da Internet e suas implicações individuais e sociais no que diz respeito às funções do educador, bem como a postura do professor frente a uma tecnologia que o aluno, em muitos casos, domina com certa facilidade; as questões relacionadas à alfabetização digital ou tecnológica do cidadão como condição básica para a manipulação e o domínio das novas tecnologias.

\section{Configuração de uma nova sociedade}

A sociedade da informação configura-se como um ambiente potencializado pelo advento das novas tecnologias e que tem como uma de suas principais características o valor crescente do conhecimento para o desenvolvimento humano e social de indivíduos e grupos, assumindo conotações não apenas de um ambiente transformado pela tecnologia, mas também, pelo processamento de informações, pelo papel estratégico do conhecimento teórico na definição de novas formas de saber, pela ênfase atribuída às atividades ligadas à educação, à formação profissional e à pesquisa em geral. É uma sociedade onde "pela primeira vez na história da humanidade, a mente humana é uma força direta de produção, não apenas um elemento decisivo no sistema produtivo" (Castells, 1999, p. 51). Dessa forma, tal sociedade constitui o ponto de partida para as análises aqui desenvolvidas.

O papel de destaque das novas tecnologias de informação e comunicação (TICs) na sociedade atual é atribuído principalmente à valorização da informação. Assim, tudo aquilo que potencialize o seu manuseio representa um elemento importante nesse processo, no qual a informação emerge como matéria-prima e a tecnologia como um meio de agir sobre ela. Nesse sentido, é possível apontar tais tecnologias como as principais propulsoras e mantenedoras da atual sociedade.

Análises que buscam uma maior compreensão de fenômenos relacionados à inserção de TICs na sociedade, ou, como sugere Benakouche (2000), da "apropriação social" dessas tecnologias, bem como de suas relações e potencialidades, revestem-se pois, de fundamental importância para que se possam desenvolver ambientes favoráveis para atuação e interação dos indivíduos na nova realidade social.

Uma das principais características das tecnologias da informação é a de diminuírem a "distância" entre o ser humano e aquilo que lhe pode ser extremamente valioso: a informação. Atualmente, um dos principais representantes dessas tecnologias é o computador. É importante destacar que o computador, enquanto tecnologia da informação, cria um novo marco no processo de evolução tecnológica na medida em que rompe totalmente com princípios anunciados por outras tecnologias, modificando a relação do homem com a máquina, a qual passa a ganhar novos horizontes e significações no momento em que tais tecnologias buscam aproximar-se do funcionamento do cérebro humano. 
Por outro lado, enquanto veículo tecnológico, as potencialidades e características do computador ganham novas dimensões, uma vez que podem fornecer acesso a ambientes propícios para a conquista e o desenvolvimento de novos conhecimentos, de interação, criação e cooperação entre as pessoas. Ao analisar essa questão, Silva (2000, p. 40) propõe a utilização do computador 'enquanto 'tecnologia cultural' e não apenas como 'um aparato técnico' materialmente objetivado, (...), mas como corpo lógico de elementos simbólico-culturais".

Feitas essas reflexões, parece plausível supor que o computador, muito mais do que um aparato tecnológico, pode representar um importante elemento no desenvolvimento cognitivo e social da humanidade, na medida em que potencializa, de uma forma jamais vista na história da raça humana, as possibilidades do homem atuar e interferir na sociedade, e, enquanto criatura tecnológica concebida pelo intelecto humano, sua utilização fica condicionada às vontades, às aspirações, aos desejos e aos objetivos de seu criador.

Analisado a forma como as TICs têm transformado a sociedade em todos os seus setores, infere-se que o acesso às tecnologias da informação pode configurar tanto um elemento determinante de sucesso quanto de fracasso individual, social ou corporativo. Ao se referir a essa nova modalidade de exclusão, Silva (2000, p. 31) afirma que "ela reproduz a velha separação entre o topo e a base da pirâmide, desta vez como "inforicos e infopobres' onde a referência de base é o domínio do "novo alfabeto"'. Ao citar Cádima e a expressão "hovo alfabeto" por ela utilizada, o autor sugere a emin ência de um novo analfabetismo funcional para o século XXI: o tecnológico.

$\mathrm{Na}$ sociedade atual, é possível perceber que médicos, advogados, administradores de empresa, economistas e, sobretudo, professores saem das universidades, analfabetos em termos de tecnologia e, o que é mais preocupante, permanecem nessa condição. É importante que os professores e profissionais de todas as áreas tenham a capacidade de interagir ampla e versatilmente com as tecnologias, porém, como sugere Chaves (2000), "com os pés pla ntados em sua área de atuação".

A alfabetização tecnológica dos professores, torna-se ponto fundamental na tarefa de escolher entre "inserir" a tecnologia na escola e "sofrer" seus impactos, ou possibilitar a "interação" com e através da tecnologia na esco la e suas implicações, possibilitando que professor e aluno possam descobrir, compreender, interagir e contribuir para "modificar" o mundo que os cercam.

\section{Escola e a democratização do conhecimento}

A escola, instituição deliberadamente projetada para propiciar a construção de conhecimento, possui papel fundamental na sua democratização, que, nesse sentido, constitui muito mais do que um ato de cidadania; é uma ação concreta na construção de uma sociedade mais justa e igualitária. $\mathrm{O}$ acesso ao conhecimento significa, entre outros aspectos, colocar o ser humano em contato com um ambiente rico em informações, interativo, cativante e desafiante; um ambiente que pode vir a se tornar um dos propulsores do desenvolvimento intelectual e social do homem, em especial se a escola atuar como um elemento ativo desse processo.

Para tanto, a "apropriação social" das TICs por parte das escolas é necessária e estratégica, porém não no sentido de fornecer o mesmo ensino com outros suportes, mas 
de abrir novos horizontes de interação e de desenvolvimento aos indivíduos, possibilitando ao ambiente escolar a superação de sua condição de reprodutor para assumir seu papel de produtor de novos conhecimentos.

Neste contexto, destaca-se àquela tecnologia que vêm resignificando o próprio conceito de "Computador" como objeto tecnológico autovalorado, atribuindo -lhe gradativamente o papel de simples interface: a Internet. A rede mundial de computadores, em função do nível de interatividade que proporciona e de sua flexibilidade apresenta um potencial comunicacional jamais detectado em tecnologias precedentes.

Referindo-se à modalidade comunicacional interativa, viabilizada pelas novas TICs, em especial pela Internet, Silva (2000, p. 11) destaca que o emissor "constrói uma rede (não uma rota) e define um conjunto de territórios a explorar, (...) abertos a navegações e dispostos a interferências e modificações, vindas por parte do receptor. Este, por sua vez, torna-se (...) co-autor, co-criador, verdadeiro conceptor". As novas tecnologias interativas 'permitem a participação, a intervenção, a bidirecionalidade e a multiplicidade de conexões. (...) rompem com a linearidade e com a separação emissão/recepção" (p. 13).

Quanto à flexibilidade da Internet, pode-se imaginar que esta se refira, entre outros elementos, ao fato de que tanto é possível encontrar referências sobre praticamente todos os assuntos na rede quanto fazer dela um meio de emissão de qualquer tipo de informação ou conhecimento. Pode-se apontar a questão da flexibilidade da Internet como um dos propulsores do crescimento exponencial da rede, sobretudo em residências e instituições de ensino públicas e privadas.

Atualmente, a Internet figura como um dos principais destaques das TICs, por possibilitar a cada usuário, entre outras funções, selecionar, receber, tratar e enviar qualquer tipo de informação, através de ambientes propícios e extremamente favoráveis à circulação dessas em uma dimensão inédita, constituindo o que Castells (1999, p. 369) chama de "espinha dorsal da comunic ação global mediada por computadores".

A possibilidade de interação, de comunicação entre indivíduos e grupos e de troca de informações entre eles, torna-se possível e potencializa-se em função dos serviços e das características da Internet, podendo significar um grande diferencial para a criação de ambientes educacionais que privilegiem aspectos como colaboração, interação e coletividade.

A oportunidade que a Internet apresenta, de resgatar a questão da coletividade, é lembrada por Lévy $(1999$, p. 14) quando declara que as tecnologias da informação são, de fato, "responsáveis por estender de uma ponta à outra do mundo as possibilidades de contato amigável, de transições contratuais, de transmissão do saber, de trocas de conhecimentos, de descoberta pacífica das diferenças, representando não apenas mais uma tecnologia da informação, mas um verdadeiro veículo de socialização".

As potencialidades da Internet no meio educacional abrem um leque muito amplo de utilizações e podem ir muito além do que uma visão mais otimista poderia imaginar. Entretanto, é necessário que se tenha claro que a simples conexão física das escolas à rede não é garantia de um incremento significativo na busca da construção da cidadania e do conhecimento. Segundo Pretto (2000), "não pre cisamos de Internet nas escolas, mas sim de escolas na Internet (...) Fortalecer as culturas locais e disponibilizálas na rede mundial, é fortalecer o cidadão". 
A possibilidade fornecida pela Internet de ir além das quatro paredes de uma sala de aula, buscando mais do que o registrado em cadernos, livros e quadros, rompe com práticas educacionais que separam emissão e recepção, propiciando a criação de novas práticas, mais intensas e interativas.

\section{Metodologia do desenvolvimento da pesquisa}

Em razão do tema proposto - refletir sobre as potencialidades da Internet como elemento de democratização do conhecimento e de superação das diferenças sociais na sociedade da informação -, desenvolveu-se uma experiência de campo junto a um grupo de jovens pertencentes à Escola Estadual de $1^{\circ}$ grau - Escola Aberta de Passo Fundo RS, comumente chamada de Escola Aberta, destinada à educação de jovens de baixa renda e que vivem nas ruas da cidade.

O estudo foi desenvolvido no Laboratório de Software Educacional - LSE - da Faculdade de Educação da Universidade de Passo Fundo, sendo utilizadas máquinas multimídia com acesso à rede Internet. O LSE funciona em uma sala reservada e propícia ao desenvolvimento de atividades acadêmicas e de pesquisa que necessitem de recursos computacionais.

Salienta-se que o objetivo principal da realização das atividades propostas aos jovens da pesquisa, foi possibilitar a sua interação com e através da Internet a fim de fornecer o maior número de possibilidades de reprocidade de trocas e de comunicação ao grupo, bem como de busca de informações consideradas por eles, importantes para o seu desenvolvimento enquanto cidadãos.

Para tanto, antes do início das atividades, o ambiente onde deveriam ocorrer os encontros (LSE) era devidamente organizado para acolher o grupo de jovens. Os computadores, bem como os programas a serem utilizados, a fim de possibilitar níveis de interação satisfatórias e favoráveis à observação, eram devidamente preparados para minimizar os trabalhos de manipulação ou aprendizagem de atividades relacionadas ao computador enquanto objeto tecnológico, possibilitando aos jovens uma maior dedicação aos aspectos relacionados à interação com e através da Internet.

Todas as atividades propostas foram desenvolvidas individualmente pelos jovens e consistiram em: práticas de navegação dirigida, navegação livre, atividades de comunicação síncrona e assíncrona e construção de homepage pessoal.

Para as atividades de navegação dirigida, foram selecionados alguns sites entre os quais o grupo podia escolher os que mais lhe agradassem. A seleção dessas páginas foi feita com base nas informações fornecidas pelos próprios sujeitos da pesquisa. Além dos sites elencados, outros foram relacionados, priorizando aspectos sociais, políticos e culturais. A relação dos sites utilizada durante essa atividade, pode ser encontrada em http://vitoria.upf.tche.br/ teixeira/mest/sites.htm.

Nas atividades que possibilitaram a navegação livre do grupo segundo seus próprios interesses, o grupo foi orientado a utilizar algumas ferramentas de procura na Internet, como, por exemplo, o site brasileiro de busca, Cadê (http://www.cade.com.br), que possibilita a localização de páginas na Internet que tratam de informações específicas, localizadas a partir da digitação de palavras relacionadas. 
Nas situações de comunicação assíncrona, o grupo pôde enviar mensagens pela rede segundo suas próprias necessidades e preferências. Embora não tenha sido efetuada a criação de e-mails pessoais para cada um dos jovens, estes puderam, a partir de formulários disponibilizados pelos próprios sites acessados, redigir suas mensagens e enviá-las. Quando do preenchimento destes formulários, além do endereço residencial, era solicitado um endereço eletrônico para o recebimento de eventuais respostas, o email informado era o do próprio pesquisador (teixeira@upf.tche.br), a fim de que pudessem também servir de material a ser analisado.

Nas atividades de comunicação síncrona com outros participantes da rede, propôs-se a participação em salas de bate-papo. Esses momentos ocorreram através do acesso a páginas que fornecem tal serviço. Uma vez escolhidas as salas de bate-papo, os sujeitos passavam a interagir com os demais integrantes da sala.

$\mathrm{Na}$ atividade de criação de homepages individuais pelos jovens, cada um pôde decidir o conteúdo e a forma como deveriam ser organizadas as informações. O objetivo dessas atividades não consistia em priorizar aspectos técnicos e gráficos de construção, mas, sim, fornecer-lhes a possibilidade de poderem participar e contribuir ativamente na construção da rede

\section{Apresentação e análise dos resultados}

Com o objetivo de sintetizar as observações feitas durante a experiência de campo realizada, alguns pontos podem ser elencados. $\mathrm{O}$ primeiro diz respeito ao papel das tecnologias no cotidiano dos jovens. Observou-se que, embora algumas tecnologias da informação, como, por exemplo, a televisão e o rádio, façam parte do dia-a-dia do grupo, demandam apenas uma postura de receptores passivos por parte dos jovens, e não de emissores de informação e de conhecimento. Tal postura pôde ser verificada igualmente, na concepção inicial da rede para os envolvidos.

Ainda que o grupo nunca tivesse interagido com a Internet, pôde-se observar, além da rápida apropriação de técnicas de manuseio e utilização da tecnologia disponibilizada, uma postura dinâmica por parte dos jovens frente a essa tecnologia, na medida em que tomavam, por si só, iniciativas e decisões sobre o melhor caminho a tomar, as informações a serem emitidas e as possibilidades presentes na rede;

Neste ponto, pode-se observar que a rota de navegação tomada pelos jovens estava intimamente ligada ao seu cotidiano e seus valores, na medida em que, inicialmente, priorizaram o acesso a páginas que contêm elementos de uma cultura de massa, como, por exemplo, programas de auditório.

Com o desenvolvimento das atividades propostas, gradativamente foi possível verificar que, antes de utilizar a rede como elemento de diversão, a concepção de que poderiam, de alguma forma, auxiliar na mudança de condição de vida, era crescente e freqüentemente presente.

Vislumbrou-se, igualmente, o fator motivador existente na utilização das novas tecnologias em ambientes de caráter educacional, tanto no sentido de fomentar a participação dos alunos em atividades propostas, nas quais predominem a participação e a comunicação, quanto no sentido de fornecer um elemento importante na busca e na construção de novos conhecimentos. 
Finalmente, pôde-se detectar, no decorrer das atividades, uma grande preocupação por parte dos jovens com relação a aspectos relacionados com a expressão escrita e com sua localização geográfica, podendo, nesse ponto, ser considerada como mais uma possibilidade de auxílio no desenvolvimento de atividades inter e transdisciplinares; Verificou-se também, que a Internet constituiu-se num veículo de socialização e de comunicação pleno na medida em que possibilitou diferentes níveis de expressão por parte dos jovens, sem que aspectos como nível social ou de escolarização fossem por eles encarados como limitadores no processo de interação.

A partir da pesquisa realizada, pôde-se detectar que a utilização da Internet para os jovens demonstrou-se importante no processo de democratização do conhecimento e de busca de melhoria na condição de vida por parte dos sujeitos

\section{Considerações finais}

No estudo, verificou-se que: embora a Internet seja uma tecnologia que não faz parte do cotidiano dos jovens da pesquisa, sua apropriação ocorreu de maneira dinâmica e espontânea; em uma realidade com tantos problemas sociais, como é o caso do grupo pesquisado, a Internet assume caráter social na medida em que possibilita aos indivíduos a livre expressão de suas idéias e anseios, potencializando as atividades de interação pessoal e de troca de informações com outros indivíduos; a Internet pode fornecer um incremento significativo tanto no acesso quanto na construção de novos conhecimentos, contribuindo, dessa forma, para a superação de situações de desigualdade e de seletividade social, provenientes da divisão digital.

\section{Referências bibliográficas}

BENAKOUCHE, Tamara. (2000) "Fatores sociais e culturais na utilização diferenciada de redes eletrônicas no Brasil: notas para discussão", http://www.alternex.com.br/ esocius/t-tamara.html, Outubro.

CASTELLS, Manuel. (1999) "A sociedade em rede - a era da informação: economia, sociedade e cultura”. São Paulo: Paz e Terra, v. 1.

CHAVES, Eduardo. (2000) “Informática, educação e trabalho", http://www2.mindware.com.br/textself/comput/whorta.htm, Julho.

LÉVY, Pierre. (1999) “Cibercultura”. São Paulo: Editora 34.

PRETTO, Nelson De Luca (Org.). (2000) “Globalização \& educação: mercado de trabalho, tecnologias de comunicação, educação a distância e sociedade planetária". 2. ed. Ijuí: Unijuí. (Série Terra Semeada)

- (2000) "Linguagens e tecnologias na educação", http://www.ufba.br/ Pretto/textos/endipe2000.htm, Outubro.

SILVA, Marco. (2000) "Sala de aula interativa". Rio de Janeiro: Quartet. 